\title{
A imagem e suas formas de visualidade nos livros didáticos de Português*
}

\author{
Celia Abicalil Belmiro**
}

\begin{abstract}
RESUMO: A importância do estudo da imagem e de sua utilização nos veículos de comunicação, principalmente os de caráter pedagógico, instaura, no âmbito escolar, a necessidade de se defrontar com a presença avassaladora da imagem visual no cotidiano dos sujeitos. Este texto pretende compreender os diferentes modos de visualidade em livros didáticos de Português, de $5^{\text {a }}$ a $8^{\text {a }}$ séries do Ensino Fundamental, nas décadas de 1960, 1970 e 1990. Qual o papel da escola ao se apropriar do discurso imagético e submetê-lo ao discurso pedagógico? Ao longo das décadas analisadas, como as imagens foram sendo constituídas por um discurso específico do processo de escolarização? Três abordagens teóricas, a saber, a imagem do ponto de vista funcional, semiótico e cognitivo, têm o objetivo de compor um conjunto de reflexões cujo eixo é a relação ensino-aprendizagem.
\end{abstract}

Palavras-chave: Imagem, livro didático, leitura, ensino-aprendizagem, escolarização

\section{Introdução}

Ao longo da história de inserção da imagem em diferentes instâncias do espaço escolar e materiais produzidos para esse espaço, o livro didático vem se destacando como um importante suporte de sua veiculação em

* Este texto é resultado de trabalho apresentado na $22^{\mathrm{a}}{ }^{\mathrm{a}}$ Reunião Anual da ANPEd, em Caxambu, set./99.

** Pesquisadora do Ceale; docente da Faculdade de Educação da Universidade Federal de Minas Gerais. E-mail: belmiro@fae.ufmg.br 
projetos pedagógicos. São recorrentes as situações de uso das imagens, evidenciando alguns pontos de sua contextualização sócio-histórica, em meio às políticas educacionais:

$\left.1^{\circ}\right)$ como indicador do processo de "modernização" por que vem passando o suporte;

$\left.2^{\circ}\right)$ como um meio de trazer para dentro da sala de aula linguagens renovadas que circulam na cotidianeidade das populações;

$3^{\circ}$ ) como tradução didático-metodológica de um ponto de vista sobre as relações de ensino-aprendizagem da língua portuguesa e outras linguagens. As reflexões a seguir pretendem compreender o uso de imagens ${ }^{1}$ em livros didáticos de Português dos fins dos anos 60 e início dos 70, em contraposição aos anos 90, orientadas por um contexto sócio-histórico e teórico.

Algumas questões iniciais podem apontar na direção de um olhar investigativo: $O$ que possibilitou o surgimento das chamadas ilustrações nos livros didáticos? Por que a imagem passou a ser utilizada nos manuais didáticos de Português preferencialmente a partir do final da década de 1960 ? Quais os procedimentos para seu uso? Com que fins a imagem surge nesses livros? Por que e como as ilustrações passam a ser consideradas parte de um saber autorizado, que pode e deve ser didatizado? Que diferenças fundamentais de usos e funções das imagens podem ser encontradas nos livros didáticos dos fins dos anos 60 em comparação com os dos anos 90 ? O que permaneceu e o que não resistiu? Como é possível construir textualidade (coesão e coerência) na relação das imagens e através delas com o texto escrito dispostos nas páginas de um papel em branco?

É interessante observar como os anos 90, principalmente nesse fim de década, vêm apresentando mudanças nas propostas de construção de seus projetos pedagógicos. Elas são mais abrangentes, interdisciplinares, integradoras, holísticas, o certo é que o paradigma está mudando. A presença de novas tecnologias no mundo escolar faz com que se repensem formas de atuação do professor. As representações que se fazem hoje do espaço de aprendizagem mostram a necessidade de um professor mais ágil, atualizado e pronto para novos desafios. É uma carga muito pesada para quem tem deficiências na sua formação inicial e não tem facilidade, pela própria gestão do tempo escolar, entre outras causas, para investir em uma formação continuada. 
O livro didático é hoje, por isso e por vários outros motivos, ${ }^{2}$ uma importante referência para o professor, para o aluno e para a família do aluno. ${ }^{3}$

\section{Algumas reflexões sobre 0 estatuto da imagem}

Para se compreender o uso escolar da imagem no suporte livro didático, é conveniente refletir, inicialmente, acerca de diferentes conceituações de imagem, a partir de três grandes eixos que discutem a natureza de sua constituição: o primeiro eixo, correntes que tendem para seu caráter de convencionalidade, enfatizando a criação de códigos próprios; o segundo, correntes que apontam para a semelhança da imagem com o dado real, como um espelhamento do mundo; ou, ainda, um terceiro, que se identifica com a idéia de conexão física, marca luminosa indicativa da existência do objeto, a exemplo da fotografia.

É possível, primeiramente, compreender a imagem do ponto de vista funcional, isto é, suas possibilidades de interação, nas palavras de Maffesoli (1995, p.103), de "religação" social. Assim, entendem-se os diferentes usos das imagens na vida social como recorrência ao cotidiano, onde os objetos são reconhecidos imediatamente pelo engendramento de uma sociabilidade integradora que ressignifica o mundo de modo menos utilitário; anuncia, assim, uma espiritualidade que não se prende a indicadores religiosos, mas que está mais perto dos atores sociais, nos segredos dos microgrupos, na sociabilidade da vizinhança, no ambiente afetuoso das relações de amizade, na viscosidade das aderências religiosas, sexuais, culturais, todas as coisas que precisam de imagens que lhes sirvam de catalisador. Na verdade, a discussão proposta por esse autor pretende apontar o sentido agregador das imagens, sentido que contribui para a atração social. Distante da preocupação em produzir conteúdo político, estético ou social, o interesse desse autor se dirige para descobrir que imagens religam tribos ou a massa, que a sociabilidade é engendrada pelas imagens produzidas no e pelo cotidiano social. A construção de uma realidade coletiva e múltipla abre espaços diferenciados para experiências singulares, individuais e únicas. Mas essa é uma via de mão dupla, em que as individualidades se aproximam ou se distanciam na constituição de processos de ressignificação de mundo. Um bom exemplo é a reflexão de Elias Canetti em seu livro memorialista Uma luz em meu ouvido:

Com este quadro, diante do qual fiquei parado muitas vezes, conheci o que é ódio. Eu o sentira cedo na vida, cedo demais, com cin- 
co anos, quando quis abater com o machado minha companheira de brinquedos. Mas não temos conhecimento daquilo que sentimos; é necessário que o vejamos nos outros para que o reconheçamos. Somente se torna real aquilo que reconhecemos quando, antes disso, o experimentamos. (Canetti 1989, p.113)

É possível que seja isso que Maffesoli queira enfatizar ao se referir à "imagem refletida e à tomada de consciência da pluralidade do real. Para ele

podem-se mostrar coerências, estabelecer correlações, mas não é possível fazer sistemas com imagens. Talvez seja isso que tenha tornado menores todas as propostas de pensamento que se apoiaram nela [imagem refletida]. Pelo contrário, essa união do pensamento e da própria coisa é perfeitamente pertinente para descrever um mundo complexo, onde reina o heterogêneo. A possibilidade de ilustrar, de nomear, de descrever, mesmo que não tenha a virtude generalizante do conceito, permite fazer destacar a razão interna (ratio seminalis) que anima cada coisa. (Op. cit., p.105)

Embora não seja o caso, aqui, de pensar a pertinência ou não da aposta de Maffesoli na "razão sensível", ajuda-nos a sua idéia de reencantamento do mundo, em que as imagens serviriam de elemento catalisador às "pequenas utopias intersticiais", isto é, aos ritos particulares, para compreender essa razão interna que anima cada coisa.

Os sistemas de referência que os grupos criam e nos quais se reconhecem são constituídos também por imagens que instauram laços de comunhão entre os homens. A idéia de que pela imagem eu me aproximo do outro, me uno ao outro, favorece a qualidade erótica da imagem de "conjunção, copulação". Esse caráter relacional estabelecido pela imagem e o conjunto das pessoas e das coisas é que define a imagem e constitui o modo de sua existência. Assim, a imagem factual, efêmera, sensual está próxima da natureza indicial que revela a presença de algo no qual a imagem se integra, isto é, é uma imagem indiciária cuja representação se dá por contigüidade física do signo com somente este referente, é um traço do real. Da mesma forma, enfatiza sua natureza simbólica que possibilita constituir esse conjunto de significados do todo social, e é constituída por ele, vale dizer, é uma imagem que se torna significativa por sua ancoragem nos conteúdos resultantes da criação imagética e, não, na realidade mesma. Assim, refletir acerca de possíveis leituras de imagens pode significar também investigar que padrões de visualidade um dado contexto sócio-histórico organiza e conforma. 
Talvez seja proveitoso fazer um paralelo ao movimento que essa sociabilidade cria em direção ao conhecimento, com base na noção de letramento proposta por Soares:

ter-se apropriado da escrita é diferente de ter aprendido a ler $e$ a escrever: aprender a ler e a escrever significa adquirir uma tecnologia, a de codificar em língua escrita e a decodificar a língua escrita: apropriar-se da escrita é tornar a escrita "própria", ou seja, é assumi-la como sua "propriedade" (1998, p. 39).

Dessa forma, entende-se que são as práticas sociais de escrita que determinam as posições dos sujeitos e o seu valor lingüístico na atribuição dos papéis sociais. Isto é tornar a escrita própria. O conceito de letramento vem ultrapassar noções como homogeneidade, relações biunívocas, sistema fechado, estrutura, e vai ao encontro da heterogeneidade própria da natureza das práticas sociais significativas. No caso das imagens, elas vêm nos povoando e constituindo modos de convivência. Daí não caber, nesse desenho teórico, a afirmação de que podemos assumir imagens como uma "propriedade". Isso significa que a sociabilidade - naquilo que ela requer das imagens para se constituir - não reivindica uma aprendizagem, isto é, domínio de uma técnica. Esse viver um evento em imagem é a face imagética do letramento verbal; na maioria das vezes, somos "letrados" visualmente mas analfabetos visuais, uma vez que não tivemos um aprendizado sistematizado de modos de "ler" uma imagem: como se organizam seus componentes, a seleção ou não de cor, angulação etc.

Portanto, essa primeira abordagem da imagem possibilita dizer que a qualidade intrínseca de sua natureza indicial e simbólica vem contemplar o viés relacional da imagem como atividade social.

Um segundo ponto de vista, que utiliza outros procedimentos para a compreensão da imagem, vem trazer a necessidade de explicitação de um código que pode e deve ser dominado para implementar estratégias de leitura da imagem. Essa não é uma questão fácil de conduzir, uma vez que diferentes pesquisadores já travaram polêmicas sobre o estatuto de dependência, ou não, lingüística da imagem. Santaella (1997, pp. 39-41) traça um quadro das teorias que sustentam essa discussão.

O que nos importa no momento é tentar esclarecer as implicações da convencionalidade dos dispositivos técnicos, que determinam uma visualidade própria sem correspondência direta com os padrões de visualidade do nosso 
olhar. Sabe-se que o que é apreendido pela visão da máquina fotográfica não corresponde à perspectiva do olho humano; Gombrich (1960, apud Santaella 1997), enfatiza que a visão de espaços representados em perspectiva não é inata à percepção visual e que deve ser aprendida. Sabe-se, igualmente, que o que se vê é tradução de um modo de organização do olhar, que, de tempos em tempos, sofre influências das revoluções técnicas e cria novas formas de apropriação do visível, uma lógica sempre precária, porque presa a um conjunto de fatores históricos, sociais, científicos. Dessa forma, a imagem, por sua própria natureza, é mediática e, portanto, é representação.

O uso do termo alfabetização visual vem contemplar as práticas de aprendizagem da convenção para a leitura de imagens: enquadramento, distância, ângulo, corte, cor, textura etc. Este é um aspecto da relação teoriaprática que deve ser amplamente discutido nos centros de produção de conhecimento a respeito da imagem na educação, tal a importância das imagens, tanto em instâncias públicas quanto privadas do cotidiano social.

Veremos, mais adiante, como o uso das imagens nos livros didáticos sofre uma tremenda redução de suas possibilidades interpretativas, pela adaptação a uma configuração analítica que aponta para um modo de compreensão próprio de um objeto de estudo que é a linguagem verbal. A subordinação a um padrão conceitual que não Ihes é próprio faz as imagens se ajustarem a uma lógica textual de produção de sentidos linear, argumentativa e unívoca.

Um terceiro viés com que se pode definir a natureza da imagem é o que Gibson (apud Santaella, pp.39-40) chama de invariantes da percepção visual, isto é, unidades de percepção elementares que permanecem constantes quando o objeto ou o observador mudam de posição. Assim, a relação entre o fundo e figura se mantém coerente e compreensível para quem vê, posto que é assegurada coesão interna à figura e sua relação no campo visual mantém contornos invariantes. O que é percebido, então, é visto como algo análogo, semelhante à realidade, caracterizando, assim, sua natureza icônica. É o que Samain (1998, p.13) chama de "uma visualidade originária e constitutiva do ser humano". A percepção visual, entendida como uma qualidade inata ao homem e descrita com categorias próprias, resulta, por conseguinte, na dimensão cognitiva de compreensão da imagem.

\section{As décadas de 1960 e 1970}

O quadro que se configura nos fins dos anos 60 e na década de 1970 é de mudança de paradigma, o que pode ser detectado em vários aspec- 
tos da relação ensino-aprendizagem: o quadro passou a ser "de giz" (cor verde), não há o estrado em que se destaca a figura do professor e que enfatiza a relação de poder, nem os mapas, as borboletas envidraçadas e os pequenos bichos empalhados. Uns, abolidos; outros, destinados a lugares próprios. É o período de influências intensas da Teoria da Comunicação no ensino da Língua Portuguesa, um tempo em que o mundo ocidental se vê envolto por grandes mudanças de comportamento dos jovens. A televisão começa a transmitir em cores.

Assim é que a influência dos estudos sobre modelos transmissivos de comunicação, no espaço escolar, se traduz no discurso pedagógico que procura caminhos de contemporaneidade. A matéria sobre a qual os professores e alunos se debruçam é a Comunicação e Expressão (a partir da lei 5692/71); conteúdos que pretendem abordar a Teoria da Comunicação são privilegiados em sala; uma nova organização em área de estudo das linguagens aproxima disciplinas antes divorciadas, como o caso do Português e da Educação Física.

Por outro lado, é época de ampliação de vagas nas escolas brasileiras, de acesso de crianças de camadas populares aos bancos escolares, de uma mudança radical dos freqüentadores das escolas públicas.

As representações do ambiente de ensino-aprendizagem mudam um pouco, numa indicação de que a ética que dá contornos para a ação educativa sofre algumas mudanças. O livro didático abandona a limitação do pretoe-branco, isto é, a folha branca como espaço vazio para a chegada do texto em preto, e toma cor. Progressivamente, esse espaço será redimensionado qual o uso poético dos poetas concretos, como veremos em anos seguintes. Mas não é assim rapidamente, e nem facilmente, que os manuais didáticos se transformam. Nos fins dos anos 60, é possível verificar, nos livros analisados, uma tendência tênue para a cor, talvez tímida, talvez insegura. Mas é presente e, o que constataremos depois, irreversível. Assim, podemos ver o tom terra, um pouco amarronzado, um pouco alaranjado, avermelhado, em algumas imagens, acompanhando o preto ou sendo por ele delimitado. Também surge a cor nas letras de subtítulos, no sublinhado das palavras, das frases, ou mesmo, num rasgo de intensidade, como um mancha de fundo para destacar definições, conceitos, quadros sinópticos. Em outros momentos, são vistas numerações, também em marrom, que indicam a quantidade de linhas do texto.

Um aspecto que será intensamente (mal ou bem) explorado nas décadas seguintes, e que já indica a procura de um lugar definitivo nesse tipo de suporte, 
é a ilustração, inicialmente também em marrom, que introduz o texto da unidade. A semelhança de uso dessa imagem com as ilustrações em livros de literatura infantil e juvenil, até essa época, mais parece cópia. Tais como os desenhos de personagens da ficção infantil situados no início de cada capítulo, muitas vezes colocado sobre um cenário construído como fundo para as ações do protagonista, a página introdutória da unidade no livro didático freqüentemente organiza um certo olhar com o qual devemos nos aproximar do texto. Veremos, no decorrer das décadas seguintes, um salto de qualidade das imagens em livros de literatura, diferentemente das ilustrações de livros didáticos, muitas delas imaturas e inconsistentes. Nesse período, a imagem é meio de motivação para a leitura do aluno, tem como finalidade modernizar ${ }^{4}$ o objeto livro (Anexo 1). Se o assunto é uma menina estudiosa, a ilustração é uma menina sentada à mesa de estudos; se é um passeio de trem, imagem de pessoas descontraídas sentadas dentro do trem. É redundante em relação ao título do texto, uma vez que não acrescenta ou renova diferentes leituras, e não tem a preocupação de dialogar com o texto.

Hoje, essa área de trabalho, a da ilustração, é reconhecida ao ponto de interferir na constituição de um projeto gráfico específico para livros didáticos.

Outro exemplo de modernização é a falta de objetivo pedagógico no uso da imagem: num livro de $7^{\underline{a}}$ série de 1972 (Anexo 2), na parte de Estudo do Vocabulário e das Expressões, é solicitado ao aluno que escreva o nome dos animais desenhados e que são citados no interior do texto. Ora, o exercício requer do estudante que saiba, na verdade, reconhecer os animais, uma vez que não são tão comumente vistos (anta, caititu, capivara, veado). Dessa forma, o desenho não facilitará o enriquecimento do vocabulário e das expressões; ao contrário, apenas será um meio de reconhecimento de informações já dadas.

Uma outra situação de uso para a ilustração é a da visualização do conteúdo trabalhado na unidade. Assim, a função da preposição é representada no texto explicativo de um livro do início da década de 1970 (Anexo 3), a um cabo que liga dois caminhões, na cor terra. Em 1986, este mesmo conteúdo é visualizado em livro didático do mesmo autor através de duas motos coloridas (Anexo 4). Depois de 12 anos, o que mudou foi o tom moderno dado pela recorrência a um veículo moderno. A concepção de língua, de gramática e de metodologia de ensino de Português passaram maqueadas pelas cores das figuras. Afinal, ainda não era tempo de convivência de modelos lingüísticos que vinham sendo construídos, e com os quais se pesquisavam novas categorias de análise, com o cotidiano metodológico de sala de aula. 
O certo é que, até o início da década de 70, a visualidade dos manuais didáticos parece refletir a ambigüidade do convívio entre o existente e o novo. Interessante observar que, às vezes, vê-se a capa do livro repleta de estímulos visuais, contrariamente ao seu interior, sob a égide da procura da eficiência lingüística. Afinal, que caminho escolher (se é que é preciso escolher): a desistência da predominância da linguagem verbal, pela interferência da presença das imagens no convívio da página, ou o senso aguerrido de permanência de um saber constituído por uma cultura grafocêntrica?

\section{A indústria cultural e a construção de um novo objeto}

Ao longo da década de 70, aí sim, espelha-se toda a pujança dos anos rebeldes: cores, fotografias, desenhos, histórias em quadrinhos, e tantos outros instrumentos que possam contribuir para a absorção de teorias da comunicação que influenciam a produção do conhecimento lingüístico e dos livros didáticos. Do mesmo modo, é como se as cores e formas rompessem o espaço em branco da folha para anunciar a existência de outros códigos de comunicação e novas formas de sociabilidade no interior da escola. É fundamental, porém, recorrer às seguintes perguntas para entender a nova rede de relações que se estabelece: Quem, na verdade, está anunciando essa "novidade"? Para quem?

A indústria cultural, através da apropriação do discurso da comunicação, contamina o discurso pedagógico e faz-se presente por meio da produção de novos materiais a serem consumidos na escola. O livro didático de Comunicação e Expressão, como se estava habituado a ver, sofre uma transformação radical e passa a ser um suporte para veiculação de outras linguagens, não só os conteúdos de Língua Portuguesa. Dirigindo um olhar retrospectivo para essa época, pode-se propor como reflexão a idéia de que já aí se instaura o cerne da tensão com a qual hoje convivemos, qual seja, que espaço de existência define o objeto livro? E, nesse caso, especialmente o livro didático? Osman Lins denuncia o uso abusivo das ilustrações nesses compêndios:

Sempre houve ilustrações nos livros didáticos. Em certas matérias (Geografia, Botânica e outras) chegam a ser indispensáveis. Tudo, porém, dentro de certa medida. Além disto, outras disciplinas, ao menos a partir de determinado nível, podem prescindir desse recurso; ou devem usá-lo com a máxima parcimônia. E nenhuma, creio, seria menos propícia à pletora de recursos visuais que, justamente, Comunicação e Expressão. (1976, p.134) 
Se, através de seu texto, é possível depreender uma crítica à falta de qualidade gráfica, a diversas inadequações de uso, ou, mesmo, ao modo de construção de leitor pretendido, essa afirmação de Lins denuncia inquietude perante a ocupação de espaço, nos livros didáticos, das linguagens visuais. É como se fosse possível perder o lugar da letra, da língua, do texto, não acreditando na capacidade do aluno de se locomover na pluralidade de linguagens:

Que se pode esperar, mais tarde, da capacidade de leitura - e da compreensão do texto - de alunos tão mimados pela imagem? Alunos aos quais se ensina a língua com tão abundantes suportes visuais habituar-se-ão ao severo preto-e-branco dos textos? Serão, por sua vez, capazes de exprimir-se sem o auxílio da imagem, quando isto lhes for exigido? (p.137)

Para além do receio ou pudor diante do novo, o certo é que vários livros desse período usam cores fortes, desenhos, recortes de jornal, fotografias, num tal emaranhado de coisas a ver que se dificultam a clareza dos objetivos e a condução de estratégias de leitura para a construção do que, na época, se concebia como um leitor crítico, consciente e com domínio da linguagem em uso. São diversos exemplos de situações de comunicação (Anexo 5) em que se usam sinais de trânsito, trocam-se as falas dos personagens, invertem-se as orientações de relação dos personagens, enfim, todos com o objetivo fundamental de criar uma infinidade de situações de comunicação para que os alunos possam discernir e escolher a mais adequada. O que acontece, porém, é que muitos projetos didáticos feitos livros não conseguiram, nessa época e ainda em nossos dias, criar modos de convivência harmoniosa do discurso estético com o discurso escolar. Ou melhor, não se conseguiu, em muitos manuais, gestar propostas de trabalho que relacionassem o discurso estético e o discurso pedagógico, sem reduzir a especificidade do discurso estético pelo filtro pedagógico. Vale a pena pensar se, e como, se sustenta, nos dias de hoje, uma "leitura crítica das imagens". Nesse sentido, vale resgatar o conceito atribuído por Soares ao termo escolarização:

É a esse inevitável processo - ordenação de tarefas e ações, procedimentos formalizados de ensino, tratamento peculiar dos saberes pela seleção, e conseqüente exclusão, de conteúdos, pela ordenação e seqüenciação desses conteúdos, pelo modo de ensinar e de fazer aprender esses conteúdos - é a esse pro- 
cesso que se chama escolarização, processo inevitável, porque é da essência mesma da escola, é o processo que a institui e que a constitui. (1999, p. 21)

Dada essa inevitabilidade, de que o saber, ao se tornar "saber escolar, se escolarize", qual o papel da escola diante da possibilidade de optar por um tratamento estético nas orientações de leitura e de formação do leitor? Os livros didáticos comportam um suplemento não-didático, próximo à experiência estética? Esta é uma grande questão para os manuais, uma vez que o objetivo maior desses livros deve ser o de fazer os alunos aprenderem.

Entendendo dessa forma a finalidade dos livros didáticos, é possível, mesmo em caráter de generalização que faz correr riscos, perceber certos procedimentos redutores que denunciam a formação de estereótipos no espaço próprio de representação escolar. Assim, diferentes conceitos do termo representação, na visão de Quin (1996, pp.225-232), podem elucidar o caráter de mediação do discurso pedagógico:

a) apresentar algo novamente, e, para isso, há que se selecionar 0 que vai ser apresentado, como apresentar, quem vai apresentar;

b) algo representativo, típico ou característico. Logo, ao se apresentar repetidamente algo da mesma forma, começa-se a criar o estereótipo;

c) falar por um grupo, ou seja, algo ou alguém representa os demais;

d) interpretação do espectador, isto é, a recepção cria diferentes níveis de compreensão e a interpretação não é assegurada antecipadamente nem da mesma forma.

Nessas circunstâncias, as ilustrações nos livros didáticos, a partir dos anos 70, passam a conviver com os textos verbais de forma completamente diferente da usual até então. Muitas vezes substituem o texto, encurtam-no, revelam um modo de selecionar a realidade, de enquadrá-la, de dizê-la. ${ }^{5} \mathrm{E}$ de induzir suas possibilidades interpretativas.

\section{A imagem na década de 1990}

A relação aluno-leitor/livro didático/indústria cultural configura-se como procedimento sempre dinâmico e cabe a nós um olhar ajustado às diferentes condições de possibilidade de seu uso. 
Os anos 90 apresentam, pois, refinamento gráfico, um leque enorme de materiais visuais e uma novidade em relação ao período anterior: maior seletividade no uso desses materiais. Depois da poluição visual própria dos setenta, vivemos, hoje em dia, um momento de maior e melhor qualidade de coexistência entre linguagem verbal e não-verbal nos livros didáticos. Assim, de modo freqüente nesse suporte, em muitos deles, os variados recursos já utilizados na década de 1970 - como fotografias, desenhos, reproduções de pinturas, tirinhas de quadrinhos, charges, propagandas etc. - são, em muitos casos, apresentados sem excesso. Vale, aqui, perguntar se nós é que nos acostumamos com essa nova visualidade ou se a organização dos manuais mudou. O certo é que hoje não tem a mesma ressonância a inquietude de Osman Lins. E mais, entendemos que a autoria significa a ingerência de um grupo de realizadores, inclusive o ilustrador. Nesse sentido, podem ser postas algumas questões: cabe ao ilustrador apresentar ao aluno sua leitura do texto por meio de imagens? Essa leitura bloqueia a capacidade de interpretação do aluno? O professor está preparado para conviver com a multiplicidade de leituras de um texto? Até que ponto o "comentário" do ilustrador possibilita explicitar o caráter dialógico próprio do ato de leitura?

Outro aspecto que parece relevante para o reconhecimento da existência e da importância da imagem em manuais didáticos é a presença do tópico aspectos visuais como um dos critérios de avaliação de livros didáticos propostos pelo MEC, para compor o conjunto de itens do Plano Nacional do Livro Didático/99.

O reconhecimento de que a ilustração faz parte do conteúdo desses livros e que, por assim ser considerada, deve também ser avaliada, aponta para uma situação que desenha os anos 90: aprender a ler imagens humaniza o homem, a alfabetização pela imagem é um meio de construir cidadania. Para isso, o aluno deve saber apreciar a imagem dos livros didáticos como arte, reconhecê-la e interpretá-la (e não somente criá-la, como se pontificava nos anos 60). Aqui se identifica um aproveitamento da imagem para o que Barthes chama, em fotografia, de Punctum. É o que toca, punge com seu gesto original, o que cria no espectador uma experiência única que transborda para o imaginário. A estética da recepção traçará um constructo teórico que definirá a importância do sujeito-leitor na produção de sentidos. A riqueza que um estudo da imagem em livros didáticos pode trazer tem correspondência nas atividades de leitura com textos, ao fazer emergir um leitor capaz de atingir diferentes posições de leitura (ou perspectivas/pontos de entrada) (Orlandi 1993, pp. 101-117).

Por outro lado, algumas categorias de análise da ilustração podem ser estabelecidas com o objetivo de compreender os diferentes usos que 
dela se faz: ${ }^{6}$ como ornamento - para deixar bonita a página; como elucidação - tabelas, desenhos científicos, etc.; como comentário - desenhos que dialogam com o conteúdo do texto; como documento - privilégio para fotografias, e assim por diante.

Interessante observar o uso das imagens fotográficas nos livros didáticos: em sua grande maioria, no sentido de garantir a existência do fato, isto é, de aproveitar a força de realidade própria da fotografia, ora para ampliar a consciência social do aluno, ora para uma aproximação mais fácil com um grupo de dados de informação considerados relevantes para o projeto pedagógico do livro.

Tratada como ilustração, a imagem tem a importância de ajudar na visualização agradável da página. Se há textos muito longos, ela serve para quebrar o ritmo cansativo da leitura. Além disso, ela pode sugerir leituras, apoiá-las do ponto de vista do enredo, construir formas, personagens, cenários, enfim, compor, junto com o texto verbal, um horizonte de leitura. É interessante observar que é mais fácil a realização desse diálogo imagemtexto em livros de literatura infantil e infanto-juvenil do que nos livros didáticos. No entanto, este é um dos espaços que mais se transformou, nas últimas décadas, em relação à diagramação, à programação visual, engendrando, inclusive, novas fontes de trabalho. $\mathrm{O}$ apuro com que muitos livros didáticos vêm sendo confeccionados não corresponde, infelizmente, às riquezas que a percepção estética da imagem pode deflagrar.

Muitas ilustrações lembram as tão usadas e castigadas gravuras sobre cavalete para que 0 aluno pudesse exercitar a descrição e a narração. A substituição do instrumental não tem paralelo com as concepções renovadas de linguagem que levam a uma reformulação da proposta pedagógica.

Em todos os diferentes usos e funções da ilustração nos livros didáticos, percebe-se que o eixo ilustração - texto - leitor não se constitui de forma simples, nem caminha na mesma direção. A suposição inicial de complementaridade nessa relação nem sempre é confirmada e, em muitos casos, a ilustração ultrapassa o texto, atrapalha o texto ou, mesmo, nada lhe acrescenta. Pior, continua como mero indicador de modernidade, sem lidar com as possibilidades de sensibilização para leituras de mundo.

\section{O professor $x$ a escola $x$ as imagens}

Nesse contexto de apropriação de novas linguagens, cabe perguntar, como sempre, e mais uma vez, qual o papel do professor? As escolas 
de formação de professores têm tratado desse assunto de forma crítica? Aliás, vale questionar, antes, se as escolas de formação têm se interessado por esse assunto.

Os livros aí estão, tomando ou não novas formas na condução das relações de ensino-aprendizagem. Deve-se assinalar, ainda, que esses manuais vêm se transformando e incorporando outros conteúdos de aprendizagem, além da língua padrão escrita. Atividades de oralidade, de leitura de imagens, entre outras estratégias de produção de sentido, mesmo com tropeços e confusões conceituais, convivem nesse suporte. Assim, para viabilizar, em sala de aula, o desenvolvimento de processos cognitivos específicos para a imagem, supõese que o professor já tenha adquirido essas habilidades.

O certo é que, nesse momento de mudança de paradigmas, os espaços de formação docente e a direção de suas políticas devem considerar a relevância desse tema e contribuir, de modo propositivo, para sua pertinência no movimento de renovação curricular pelo qual essas instituições vêm passando.

\section{Conclusão}

A importância do estudo da imagem e de sua utilização nos veículos de comunicação, principalmente os de caráter pedagógico, instaura, no âmbito escolar, o reconhecimento da necessidade de se defrontar com o movimento inevitável do novo, com a presença avassaladora da imagem visual no cotidiano dos sujeitos. Deve fazer parte, portanto, das reflexões sobre os processos de construção de conhecimento escolar, atentando para as diferentes soluções de interlocução que a mediação pela imagem propõe, para a observância de seus códigos e a violação destes, suas implicações discursivas e para a compreensão de quais sejam os processos cognitivos desenvolvidos para e através da leitura de imagens.

A escolarização, assim entendida, pode ser uma alternativa saudável para redimensionar a importância da escola num mundo cada vez mais tecnológico e virtual.

\section{Notas}

1. Isto significa dois modos, pelo menos, de entender o uso das imagens: usadas em livros didáticos e feitas especialmente para esses livros.

2. Soares (1996, pp. 53-63) analisa a existência do livro didático, abrangendo diferentes aspectos que fizeram dele o que é hoje. 
3. Não houve critério específico para a escolha dos livros analisados. Como o único dado relevante para a seleção é a data de publicação, abdicamos de mencionar a autoria.

4. O conceito de modernizar é problemático e, aplicado ao estudo de manuais didáticos, merece mais tempo de reflexão e mais espaço nas discussões acerca do livro como representação de paradigmas que orientam a construção do conhecimento.

5. Aqui cabem desejáveis e necessárias análises do ponto de vista ideológico e político, embora o propósito deste texto seja o de verificar a incidência e o tipo de permanência do texto nãoverbal nos manuais didáticos e seus desdobramentos nas produções de anos seguintes.

6. Essas categorias de análise encontram-se em Celia Belmiro \& Aracy Evangelista (no prelo).

Recebido para publicação em Outubro de 1999.

\title{
Image and its forms od visuality in didactic books of Portuguese language
}

\begin{abstract}
The importance of studying the image and its use in the media, mainly in the media with pedagogical features, establishes, in the school environment, the need to cope with the overwhelming presence of visual image in people's everyday life. This paper intends to analyze and understand the different aspects of visuality in Portuguese didactic books used in the last grades of Junior High School (from $5^{\text {th }}$ to $8^{\text {th }}$ grade of the Fundamental School in the Brazilian School System), during the 60s, 70s and 90s. Which role does school play, since it takes hold of the imagetical speech and submits it to the pedagogical speech? How have images been built by a speech that is specific to the school process, along the decades mentioned above? Three theoretical approaches, namely image seen form the functional, semiotical and cognitive points of view, aim at the constructing a set of reflections, the core of which is the teaching-learning relationship.
\end{abstract}

\section{Bibliografia}

BARTHES, Roland. A Câmara clara: Nota sobre fotografia. Rio de Janeiro: Nova Fronteira, 1984.

BELMIRO, Celia A. \& EVANGELISTA, Aracy A. "A escolarização da imagem e da imaginação nos livros didáticos". Cadernos pedagógicos e culturais. Niterói, SECT/CEN. No prelo. 
CANETTI, Elias. Uma luz em meu ouvido: História de uma vida, 1921-1931. Trad. de Kurt Jahn. São Paulo: Cia. das Letras, 1989.

LINS, Osman. Do Ideal e da glória: Problemas inculturais brasileiros. São Paulo: Summus, 1977.

MAFFESOLI, Michel. A Contemplação do mundo. Porto Alegre: Artes e Ofícios Ed., 1995.

ORLANDI, Eni P. "O inteligível, o interpretável, o compreensível”. Discurso e leitura. São Paulo: Cortez; Campinas: Edit. da Unicamp, 1993.

QUIN, Robyn. "Enfoques sobre el estudio de los medios de comunicación: la enseñanza de los temas de representación de estereotipos". In: APARICl et all. La revolución de los medios audiovisuales. $2^{2} \mathrm{e}$. Madri: Ediciones de la Torre. 1996.

SANTAELLA, Lucia \& NÖTH, Winfried. Imagem: Cognição, semiótica, mídia. São Paulo: lluminuras, 1997.

SOARES, Magda Becker. Um Olhar sobre o livro didático. Presença Pedagógica. Belo Horizonte: Dimensão, 1996.

. Letramento: Um tema em três gêneros. Belo Horizonte: Autêntica, 1998.

. "A escolarização da literatura infantil". A escolarização da leitura literária: O jogo do livro infantil e juvenil. Belo Horizonte: Autêntica, 1999. 


\section{Anexos}

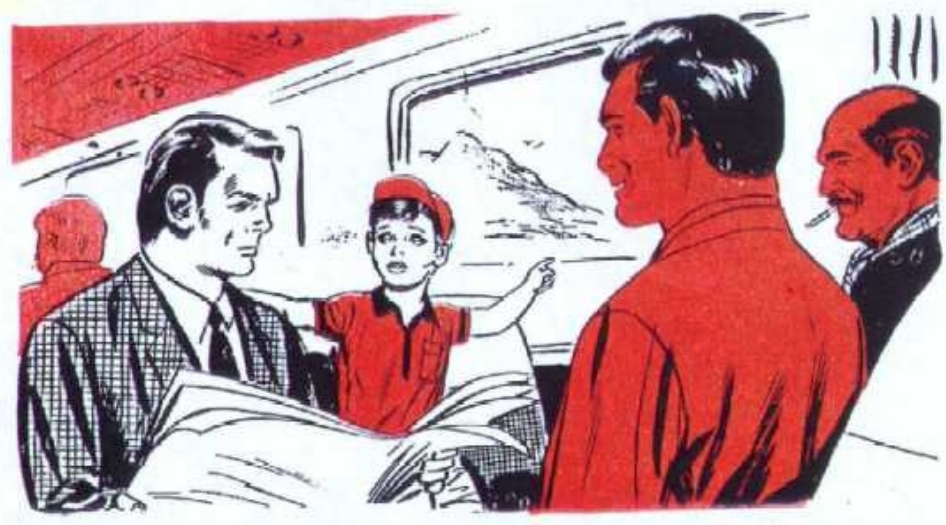

No texto que vamos ler, todos riram da pergunta que o menino fêz ao pai, exceto um homem. Nâo seria interessante saber porque êsse homem nāo riu?

Preste atençáo no significado das seguintes palavras, pois elas aparecem no texto:

tresloucado: louco, desvairado.

penedo: grande pedra.

\section{O TREM DE FEHHO}

Num trem,

Em grande disparada,

Pai e filho corriam

E ambos o que viam?

- As montanhas, os montes,

Os horizontes,

O matagal cerrado,

Os penedos,

Os rochedos,

10

Os arvoredos...

Tudo a correr com a rapidez do vento

Tresloucado!

18

\section{Anexo 1}




\section{1 - Estudo do vocabulário e das expressöes}

Só dê as respostas depois de haver consultado seu dicionário.

1) Assinale nesta relação apenas os bichos de pêlo:
(X) paca
( ) saracura
( ) cascavel
( ) jaçană
$(x)$ onça
( ) piranha
( ) poraquê
$(x)$ bugio
(X) tamanduá
(x) quati
( ) tatu
$(x)$ irara

2) Os quatro animais seguintes são citados no texto. Escreva scus nomes:
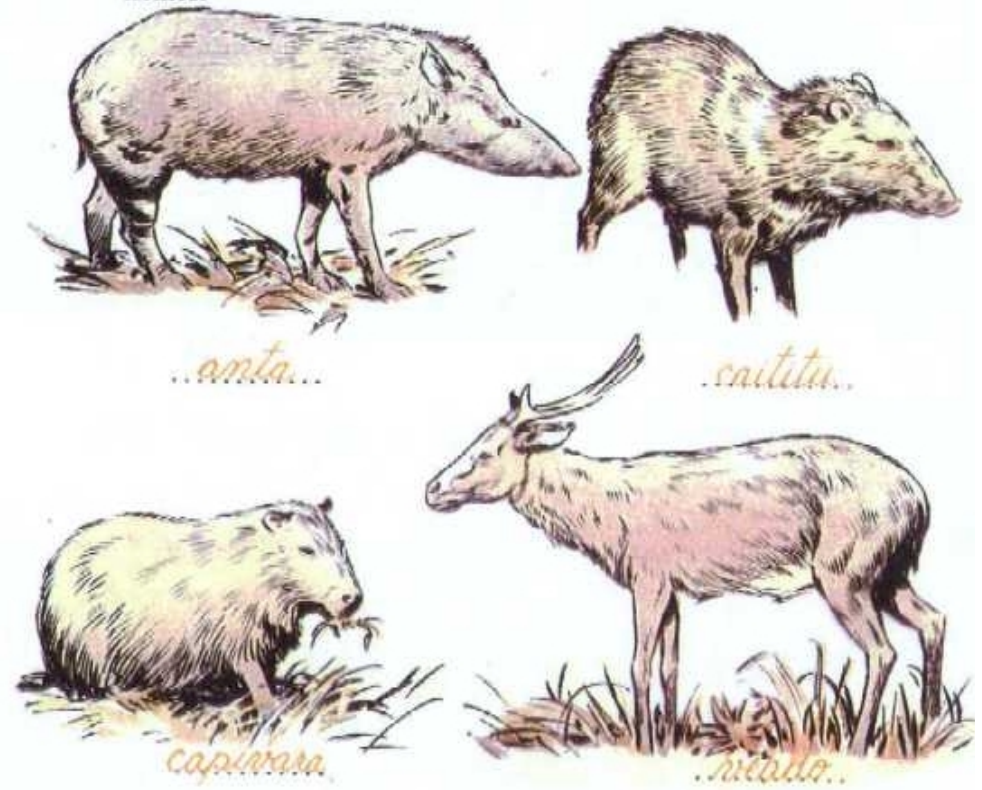

3) Na linha 7 , encontramos o colctivo vara, que ali significa coleção de caititus. Relacione as duas colunas, indicando os coletivos:
a) lobo
(a) enxame
b) peixe
(e) cáfila
c) cebola
(f) cardume
d) abelha
(c) réstia
c) camelo
(a) alcatéin 


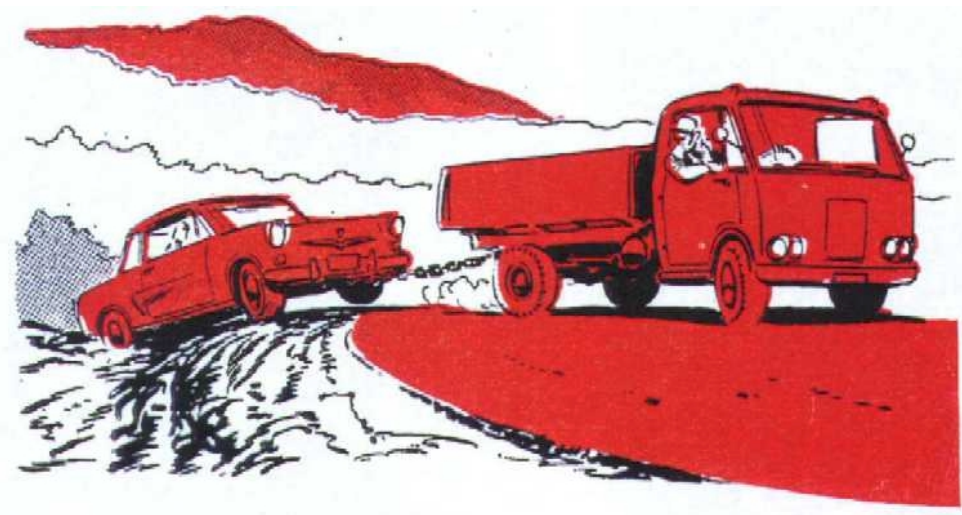

Qual é a melhor maneira de desatolar um automóvel?

\section{PREPOSIC̣ĀO}

Joăo e Pedro, dois vizinhos amigos, sáram para o serviço. João dirigia um caminhão e Pedro, um automóvel. Passados alguns minutos, o carro de Pedro cai numa valeta. João que vinha logo atrás parou, verificou as condições do carro e decidiu:

( ) chamar o guincho;

( ) levá-lo na carroceria;

(x) puxá-lo com uma corrente,

O mais viável, no momento, seria puxá-lo com a correntè e foi justamente isso que fêz João.

A corrente ligou o caminhão ao carro. Assim, o caminhão é que toma a direção, e o carro apenas o segue. Nesta situaçăo o caminhão é que manda e o carro é que recebe ordens. Usando outras palavras, podemos dizer que há o regente (o que dá ordẹm) e o regido (o que recebe essas ordens).

Em nossa língua também há os têrmos regentes e os tếrmos regidos. O elemențto que liga êsses têrrmos (regentes e regidos) não é uma corrente, mas uma palavra. Essa palavra que liga duas outras

\section{Anexo 3}




\section{Unidade 3}

\section{A - Preposição}

Qual é o modo mals prático de resolver o problema desses motoqueiros?

Alfredo e Orestes, ambos motoqueiros, resolveram conhecer o Brasil, cada um pilotando sua máquina.

Uma semana após o início da viagem, surgiu um defeito mecânico na motocicleta de Alfredo. Apesar das inúmeras tentativas de conserto, nenhum dos rapazes conseguiu fazer o motor do veículo funcionar. Era imprescindível, portanto, a atuação de um mecânico. Para isso, era preciso levar a moto até o mecânico ou trazer o mecânico até a moto naquela estrada barrenta.

Orestes achou mais prático ir buscar o mecânico, mas Alfredo argumentou que o conserto poderia depender de ferramentas especiais e de peças que o mecânico não poderia trazer.

- E preferível levar a moto, cara.

- Levar como? Só se você for empurrando. gina.

- A solução é mais fácil do que você ima-

Dizendo isso, Alfredo retirou do bagageiro uma corda resistente e ligou com ela os dois veículos. Assim, a motocicleta de Orestes rebocou a motocicleta de Alfredo até a oficina distante.

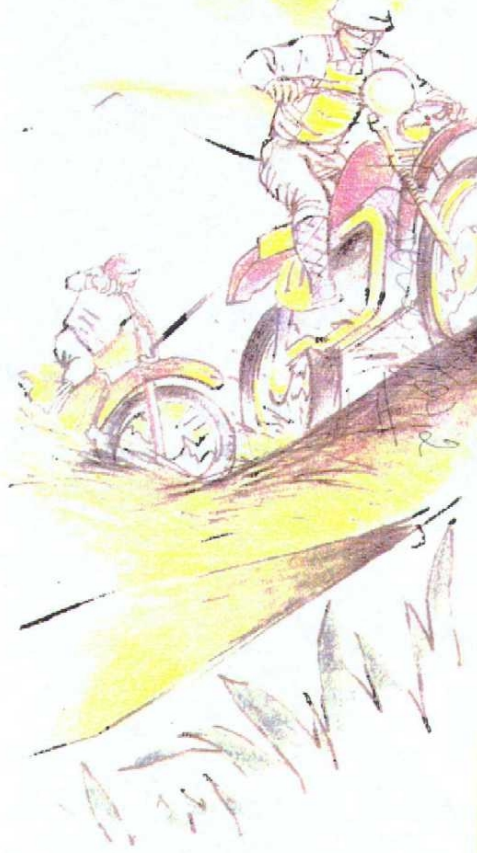

Nessa operação, encontramos três elementos importantes: a motocicleta de Orestes, que foi responsável pelo comando da ação; a motocicleta de Alfredo, que teve de obedecer ao comando da outra motocicleta; a corda, que ligou uma motocicleta à outra.

Em nossa Língua, ocorrem fatos semelhantes. Existem termos regentes, que são os mais importantes porque comandam, e os termos regidos, que obedecem ao comando dos termos regentes. Ligando-os e estabelecendo uma relação entre eles, há um elemento a que se dá o nome de preposição. Veja:

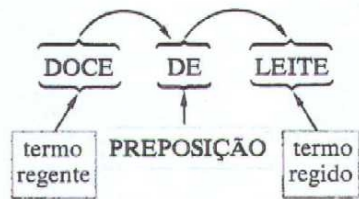

Na expressão doce de leite, a preposiçăo de serve para ligar o termo regente (doce) ao termo regido (leite), estabelecendo relação entre eles. A preposição, juntamente com o termo regido (de leite), estabelece a relaçăo de matéria com o termo regente, isto é, indica do que é feito o doce.

\section{Anexo 4}



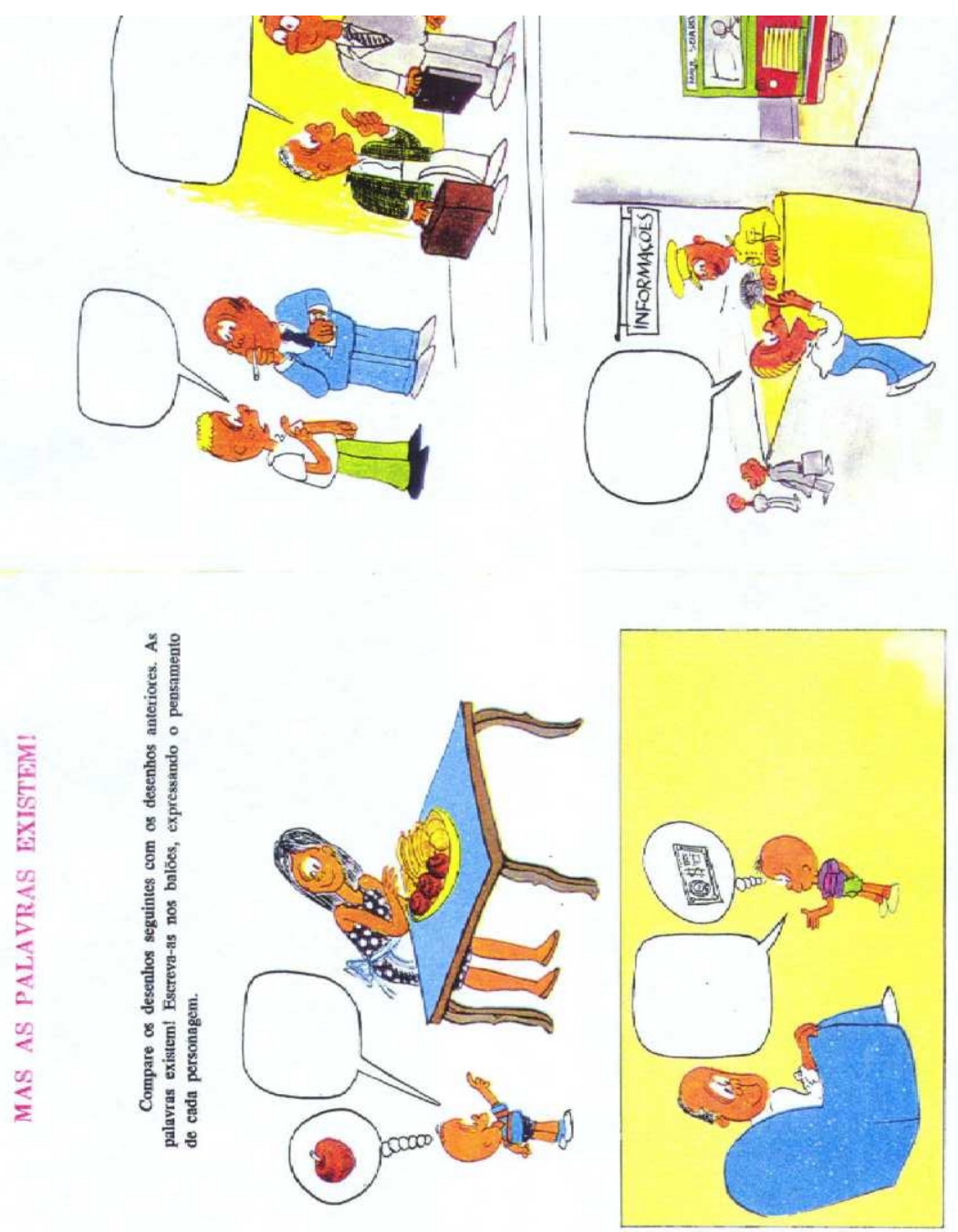

ำ

\section{Anexo 5}

